\title{
Library Information System Auditing: Monitoring and Evaluating the Software in Academic Institution
}

\author{
Lily Puspa Dewi*, Ibnu Gunawan, Raymond Weily \\ Informatics Department, Faculty of Industrial Technology, Petra Christian University, Surabaya, Indonesia. \\ * Corresponding author. E-mail: lily.puspa.dewi@gmail.com \\ Manuscript submitted April 5, 2015; accepted July 25, 2015. \\ doi: 10.17706/jsw.10.10.1140-1147
}

\begin{abstract}
The information system auditing is conducted to evaluate the readiness level of organization in managing information technology (IT). This research is conducted in library of Petra Christian University, Indonesia. In this academic institution, the library has already used IS to accommodate in its business processes. Library has done the observation to measure library users' satisfaction toward library service. In this previous observation, it has been found that the library software is not satisfied the students, lecturers and staffs as the users in providing information. Furthermore, the initial observation had found out that a lot of misinformation because human errors have often occurred in inputting data and monitoring and evaluating of library software performance has not been. Best practice is given using CMMI standard which is obtained by mapping IT processes of COBIT. Results of audit that has been conducted provide the current maturity level is level 2-managed which means the performed process have ensured that requirements are managed and executed in accordance with policy. Organization has understood the importance of managing IT in helping business processes. System development procedure has been documented. System is a form of elaboration formalization of existing activities and made it easier for users to learn to control quickly.
\end{abstract}

Key words: Auditing of information system, CMMI, COBIT, library information system.

\section{Introduction}

In today's environment, where many companies heavily dependent on information systems in running their business processes, leading the information system to be one of important asset regarding to its critical function. The well-managed information system can provide the competitive benefits and give more opportunities in business. Related to this facts, IS needs to be monitored so that IS can be run according to the company's business goal. One of IS auditing standards is COBIT (Control Objectives for Information and Related Technology). The framework of COBIT consists of high-level control objectives which are grouped into four main domains such as Planning and Organization (PO), Acquire and Implement (AI), Deliver and Support (DS) and Monitor and Evaluate (ME).

Library also take an advantage of IT/IS in performing their services to the users. This research is conducted in library of Petra Christian University, Indonesia. In this academic institution, the library has already used IS to accommodate in its business processes. Library has done the observation to measure library users' satisfaction toward library service. In this previous observation, it has been found that the library software is not satisfied the students, lecturers and staffs as the users in providing information. Although for the IS interface, users were very satisfied while other aspects of IT infrastructure, timeliness, 
and standardization they were not [1]. Furthermore, the initial observation had found out that a lot of misinformation because human errors have often occurred in inputting data and monitoring and evaluating of library software performance has not been. Related to these matters, this research emphasizes the IS auditing for monitoring and evaluating f performance (ME1) and providing IT governance (ME4) the library information system using COBIT framework by mapping with Capability Maturity Model Integration (CMMI). COBIT and CMMI framework provide an effective way in understanding the needs and priorities of the IT governance.

\section{Information System Auditing}

Information system audit (IS audit) mainly refer to truly analytical part of IT Governance by which the level of IS performance and maturity can be measured and assessed [2]. Another research stated the information systems auditing is the process of conducting analytical test and evaluating evidence to determine in monitoring and evaluating computer system, maintain data integrity, achieve the organizational goals effectively, and use resources efficiently [3].

\subsection{COBIT}

Control Objectives for Information and related Technology (COBIT) is a set of documentation for IT Governance best practices that can help auditors, the user (user), and management, to unite the gap between business risks, control needs and technical issues IT [4]. COBIT has issued by the IT Governance Institute which part of Information System Audit and Control Association (ISACA). COBIT consists of several directives, which are Control Objectives, Audit Guidelines and Management Guidelines.

\subsection{CMMI Maturity Level}

Capability Maturity Model Integration (CMMI) is a process approach that provides organizations with the essential elements of effective processes that can improve performance. CMMI can help in making the decision to process the improvement plan [5]. In staged representation of CMMI models, the improvement path is described by Maturity Level [6]. CMMI has been classified by the numbers 1 through 5 . The maturity levels consist of a predefined set of process areas. The maturity levels are quantified by the achievement of the specific and generic goals that apply to each predefined set of process areas. Maturity level 1 (initial) characterize the processes usually ad hoc and chaotic. Success at this level is based on hard work and high competence of the people who are in the organization or it can also be said the company is not running in the stable environment and frequently exceed the budget and schedule of their projects. At maturity level 2 (managed), the projects are managed and that processes are planned, performed, measured, and controlled and in accordance with the policy; use of resources and competent enough to produce a controlled output. The status of the work products and the delivery of services are visible to management at defined points. At maturity level 3 (defined), processes are well characterized and understood, and the organization has standards, procedures, tools, and methods in its process. At maturity level 4 (Quantitatively Managed), an organization has achieved all the specific goals of the process areas assigned to maturity levels 2,3 , and 4 .

All the processes including the sub processes already controlled using statistical and other quantitative techniques. Maturity level 5 (optimizing) focuses on continually improving process performance through both incremental and innovative technological improvements.

CMMI models consist of process areas. These process areas cover basic concepts that are fundamental to process improvement in any area of interest (i.e., acquisition, development, services). A Process Area is a group of connected practices, when implemented conjointly, meet a set of goals considered important for making significant improvement in that area. The CMMI Process Areas (PAs) can be clustered into four categories which are Process Management, Project Management, Engineering and Support [5]. Each 
process area is defined by a set of goals and practices. There are two type of goals and practices: Generic goals and practices (they are part of every process area) and Specific goals and practices (they are specific to a given process area). A process area is satisfied when company processes cover all of the generic and specific goals and practices for that process area. The relation among CMMI maturity levels, process area and process categories can be seen in Fig. 1 [5]. CMMI generic goals and generic practices necessary component model that can be performed by the CMMI process areas. Generic goal (GG) and Generic Practices (GP) represents the level of process capability.

\begin{tabular}{|c|c|c|c|c|c|c|}
\hline \multirow[b]{2}{*}{ Maturity Level } & \multirow[b]{2}{*}{ Acronym } & \multirow[b]{2}{*}{ Process Area } & \multicolumn{4}{|c|}{$\begin{array}{l}\text { Process Category } \\
\end{array}$} \\
\hline & & & \begin{tabular}{c|c|} 
Process \\
Management
\end{tabular} & \begin{tabular}{|c|} 
Project \\
Management
\end{tabular} & Engineering & Support \\
\hline \multirow{7}{*}{$\begin{array}{l}\text { Level 2: } \\
\text { Managed }\end{array}$} & $\mathrm{CM}$ & Configuration Management & & & & $\mathrm{x}$ \\
\hline & MA & Measurement and Analysis & & & & $\mathrm{X}$ \\
\hline & PMC & Project Monitoring and Control & & $\mathrm{x}$ & & \\
\hline & PP & Project Planning & & $\mathrm{X}$ & & \\
\hline & PPQA & Process and Product Quality Assurance & & & & $\mathrm{x}$ \\
\hline & REQM & Requirements Management & & & $\mathrm{x}$ & \\
\hline & SAM & Supplier Agreement Management & & $\mathrm{x}$ & & \\
\hline \multirow{12}{*}{$\begin{array}{l}\text { Level 3: } \\
\text { Defined }\end{array}$} & DAR & Decision Analysis and Resolution & & & & $\mathrm{X}$ \\
\hline & IPM & Integrated Project Management (includes IPPD) & & $\mathrm{x}$ & & \\
\hline & OEI & Organisational Environment for Integration & & & & $\mathrm{X}$ \\
\hline & OPD & Organisation Process Definition & $\mathrm{x}$ & & & \\
\hline & OPF & Organisation Process Focus & $\mathrm{x}$ & & & \\
\hline & OT & Organisational Training & $\mathrm{x}$ & & & \\
\hline & PI & Product Integration & & & $\mathrm{x}$ & \\
\hline & RD & Requirements Development & & & $\mathrm{x}$ & \\
\hline & RSKM & Risk Management & & $\mathrm{x}$ & & \\
\hline & TS & Technical Solution & & & $\mathrm{x}$ & \\
\hline & VAL & Validation & & & $\mathrm{x}$ & \\
\hline & VER & Verification & & & $\mathrm{x}$ & \\
\hline \multirow{2}{*}{\begin{tabular}{l|} 
Level 4: \\
Quantitatively \\
Managed
\end{tabular}} & OPP & Organisational Process Performance & $\mathrm{x}$ & & & \\
\hline & QPM & Quantitative Project Management & & $\mathrm{x}$ & & \\
\hline \multirow{2}{*}{\begin{tabular}{l|} 
Level 5: \\
Optimising
\end{tabular}} & CAR & Causal Analysis and Resolution & & & & $\mathrm{x}$ \\
\hline & OID & Organisational Innovation and Deployment & $\mathrm{x}$ & & & \\
\hline
\end{tabular}

The scope of the CMMI model may be extended with text described as 'additions'. According to the CMMI:

Fig. 1. CMMI maturity level, process area with acronyms and process category.

\section{Methodology}

This research was conducted in several stages and are gradually shown in Fig. 2. The research started with the literature study, and continued with initial data collection which is conducted in library of Petra Christian University. In this stage, IT goal should be aligned with the business goal. Every IT goal is translated into one or more IT processes. This library already used IS to accommodate in business processes several years ago, therefore, this research used domain Monitor and Evaluate (ME) of COBIT. From the COBIT and CMMI mapping, checklist is arranged for the next stage which is data collection. The fundamental methods data collection relied on by qualitative researchers are, participation in the setting, document review, direct observation, and in-depth interviewing [7]. After data collection, research carried out during the analysis of qualitative data in the data reduction method, data display and data result. In data reduction, redundant data are merged, therefore the data that has been reduced will be displayed (display data) in the form of a table or graph or pie chart or pictogram. Display data will provide information for the result of data analysis stage [8]. Validity is the degree of accuracy of the data occurs between data reported by researchers and real data. Data validation is done by member check method. The next stage is scoring the valid data which is done for quantifying the maturity level of library information system. The final stage is to prepare the IS audit report to be presented to the organization.

\section{Audit Design}

\subsection{IT Goal and IT Process}

COBIT as the most holistic IT/IS framework concentrates more on "what" to do than on "how" to do it. For this reason, it delegates "how-to-do" related issues to other tools, frameworks and methodologies. 
COBIT - CMMI mapping is concerned with some concepts for improving processes of the systems and software products. From the mapping COBIT processes to CMMI in Monitor and Evaluate domain, we found ME1 (Monitor and evaluate IT performance) and ME4 (Provide IT governance) as presented in Fig. 3 [9].

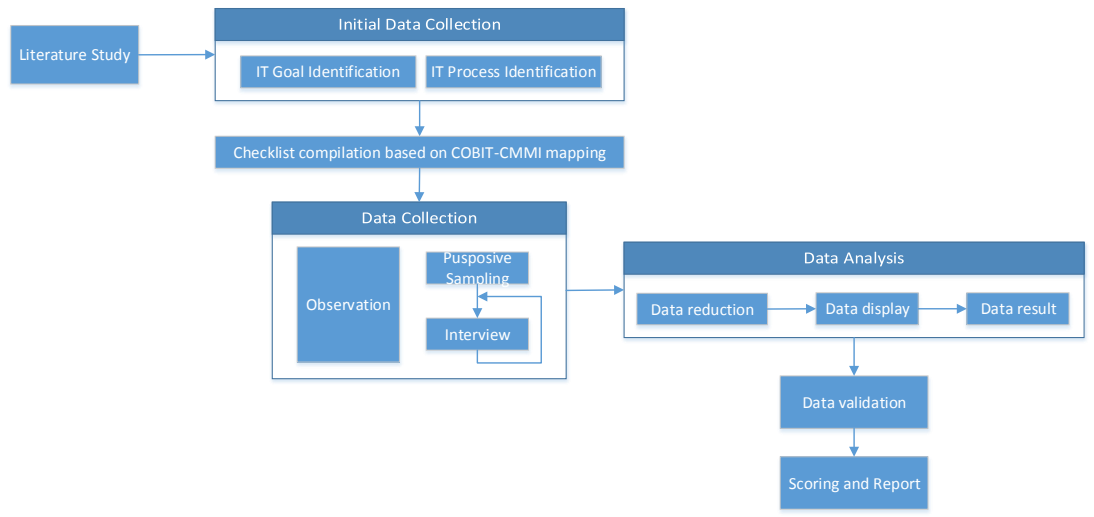

Fig. 2. Research methodology.

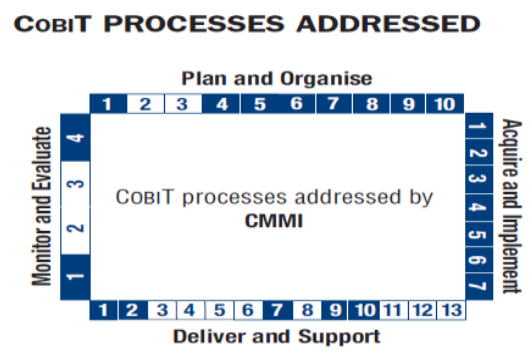

Fig. 3. Mapping COBIT processes to CMMI.

Identification of IT goals of the organization are used as reference to get the IT processes. The results of mapping between CMMI Generic Practice to COBIT Processes and Control Objectives in ME1 and ME 4 domain is depicted in Table 1 [5]. Results of identification produces seven generic processes which are GP. 2.7, GP. 2.8, GP. 2.10, GP. 3.2, GP. 4.1, GP. 5.1, and GP. 5.2.

Table 1. The Mapping of CMMI Generic Practice to COBIT in ME1 and ME4

\begin{tabular}{lc}
\hline \hline CCMI Process Capability Level Generic Practice (GP) & $\begin{array}{c}\text { CCMI Generic Practice Mapping to COBIT Processes and } \\
\text { Control Objectives }\end{array}$ \\
\hline \hline Level 2: Managed Process: & \\
\hline GP. 2.7: Identify and involve relevant stakeholder & $\begin{array}{c}\text { P01, P04, P06, P07, P08, P010, AI, AI4, AI5, AI6, AI7, DS7, } \\
\text { DS9, ME1, ME2, ME4 }\end{array}$ \\
\hline GP. 2.8: Monitor and control the process & P08.6, ME1 \\
\hline GP. 2.10: Review status with higher management & P0 8.6, ME1, ME4.6 \\
\hline \hline Level 3: Defined Process: & P08.5, ME1 \\
\hline \hline GP. 3.2: Collect improvement information & P08.6, ME1 \\
\hline \hline Level 4: Quantitatively Managed Process: & \\
GP. 4.1: Establish Quantitative Objectives for the & P08.5. ME1 \\
\hline \hline Level 5: Optimizing Process: & P08.6, ME1 \\
\hline GP. 5.1: Ensure continuous process improvement & \\
\hline GP. 5.2: Correct root causes of problems & \\
\hline
\end{tabular}




\subsection{Checklist Compilation}

The checklist aims to obtain the opinion of the respondents to determine the maturity level of library information system. The question list was developed based on the results of identification IT process. Each generic process in CMMI is broken down into several checklist and is adapted with object audit which is library information system as presented in Table 2 .

Table 2. The Checklist Compilation

\begin{tabular}{|c|c|}
\hline Generic Process of CMMI & Checklist \\
\hline \multirow[t]{9}{*}{ GP 2.7: Determine measurement goal and procedure } & Database maintenance procedure \\
\hline & Application user guide \\
\hline & Application developer guide \\
\hline & Periodic back up process \\
\hline & Database upgrade and budgeting \\
\hline & Information retrieval system: speed and accuracy \\
\hline & Versioning documentation \\
\hline & Hardware upgrade and budgeting \\
\hline & User satisfaction toward the application \\
\hline \multirow[t]{3}{*}{ GP 2.7: Response toward users' complain } & Response toward users' suggestion \\
\hline & Response toward application bug and error \\
\hline & Application bug list \\
\hline \multirow[t]{4}{*}{ GP 2.8: Progress and performance } & Performance measurement \\
\hline & Application is aligned to its goal \\
\hline & Application has been fulfilled the user requirement \\
\hline & User friendly \\
\hline \multicolumn{2}{|l|}{ GP 2.8: Percentage of measurement goal obtained } \\
\hline \multicolumn{2}{|l|}{ GP 2.8: Schedule of development } \\
\hline \multirow[t]{2}{*}{ GP 2.10: Review status with the higher management } & Review the activities, status and result of measurement \\
\hline & Solution toward the problems \\
\hline \multirow[t]{2}{*}{ GP 3.2: Collect improvement information } & Result of integrity data testing \\
\hline & Data analysis report \\
\hline \multirow[t]{2}{*}{ GP 4.1: Establish quantitative objectives for the process } & User satisfaction measurement \\
\hline & Application user statistic \\
\hline GP 5.1: Ensure continuous process improvement & System maintenance schedule \\
\hline GP 5.2: Correct root causes of problems & \\
\hline
\end{tabular}

From the checklist, question list is prepared for gathering data in interview with the respondents. These question list was distributed to the library's users including the management of each division in library which considered more aware of the IT processes related to the library business processes.

\subsection{Data Collection}

According to the data collection, this research conduct two types of data collection. The first type is observation, which is researcher took to do the daily library business processes for several days. The second method is interviewing with purposive sampling. Purposive sampling is a non-probability technique that involves the conscious selection by the researcher of certain people to include in a research [7]. This sampling technique used based on particular considerations such person is considered to be most aware of what is expected that will allow researchers to explore social situations studied object. The checklist is distributed to 8 librarians and 50 library's members. Selected respondents were representing the library users and management. 


\subsection{Data Analysis}

Data analysis in data collection took place during and after the completion of data collection within a specific time period. At the time of the interview when the answer given is considered unsatisfactory, the researchers will continue the next question to get the maximum information that is considered credible. The data analysis carried out during the analysis of qualitative data in the data reduction, data display and data result [8].

Table 3. Data Validation Result

\begin{tabular}{ll}
\hline \hline Checklist & Available \\
\hline \hline Database maintenance procedure & $\sqrt{ }$ \\
\hline Application user guide & $\sqrt{ }$ \\
\hline Application developer guide & $\sqrt{ }$ \\
\hline Periodic back up process & $\sqrt{ }$ \\
\hline Database upgrade and budgeting & $\sqrt{ }$ \\
\hline Information retrieval system: speed and accuracy & - \\
\hline Versioning documentation & $\sqrt{ }$ \\
\hline Hardware upgrade and budgeting & $\sqrt{ }$ \\
\hline User satisfaction toward the application & $\sqrt{ }$ \\
\hline Response toward users' suggestion & $\sqrt{ }$ \\
\hline Response toward application bug and error & $\sqrt{ }$ \\
\hline Application bug list & - \\
\hline Performance measurement & $\sqrt{ }$ \\
\hline Application is aligned to its goal & $\sqrt{ }$ \\
\hline Application has been fulfilled the user requirement & $\sqrt{ }$ \\
\hline User friendly & - \\
\hline Percentage of measurement goal obtained & - \\
\hline Schedule of development & - \\
\hline Review the activities, status and result of measurement & - \\
\hline Solution toward the problems & - \\
\hline Result of integrity data testing & - \\
\hline Data analysis report & - \\
\hline User satisfaction measurement & - \\
\hline Application user statistic & - \\
\hline System maintenance schedule & - \\
\hline Correct root causes of problems & \\
\hline & \\
\hline
\end{tabular}

From the data collection process, all answers from respondents will be collected into one and sought similarities. The same answer will be merged. The data that has been processed will be displayed (display data) in the form of a table. After passing through the analysis of data reduction and data display will be drawing the data result and verification as preliminary conclusions. Preliminary conclusions set temporary but will change with the discovery of evidence and the fact that strongly supports the data collection phase.

\subsection{Data Validation and Finding}

This research used member validation as data validation. Member check, also known as member validation can be described as a research stage which "the provisional report (case) is taken back to the site and subjected to the scrutiny of the persons who provided information" [10], whereby a researcher submits materials relevant to an investigation for checking by the people or participant who were the source of those materials. The crucial issue is how far the researcher's understanding of what was going on 
in a social setting corresponds with that of members in the setting. The most common form of member validation occurs when the researcher submits an account of his or her findings (such as a short report or interview transcript) for checking. The participants check to see whether a "true" or authentic representation was made of what he or she conveyed during the interview. Member checks may involve sharing all of the findings with the participants, and allowing them to critically analyze the findings and comment on them [11].

The recapitulation as the result of data validation can be seen in Table 3. The result shows availability of checkpoint as a mapping CMMI to COBIT in ME1 and ME2 domain. From this approach, we can found the maturity level 2-Managed has been fulfilled 14 of 15 point in this library information system.

\section{Conclusion}

The conclusion obtained from the audit process of library information system applications include planning and domain selection consists of the identification of IT goals and IT processes, data collection, data analysis, data validation and measurement strategies. From the mapping CMMI and COBIT in ME1 and ME2 domain, the identification IT processes produce seven generic processes which are GP. 2.7, GP. 2.8, GP. 2.10, GP. 3.2, GP. 4.1, GP. 5.1, and GP. 5.2.

The research measure the library information system governance current maturity level which is on average maturity level 2-Managed. Organization has understood the importance of managing IT in helping business processes. System development procedure has been documented. System is a form of elaboration formalization of existing activities and made it easier for users to learn to control quickly.

\section{References}

[1] Library of Petra Christian University. (2014). Laporan Tahunan (Annual Report). Surabaya.

[2] Mashour, A., \& Zaatreh, Z. (2008). A framework for evaluating effectiveness of information systems at Jordan banks: An empirical study. Journal of Internet Banking and Commerce, 13(1), 1-14.

[3] Ron, W. (1999). Information System Control and Audit. Queensland: Prentice Hall.

[4] IT Governance Institute Team. (2007). COBIT 4.1. USA: IT Governance Institute.

[5] Mallette, D. (2007). COBIT Mapping: Mapping of CMMI for Development V1.2 with COBIT 4.1. USA: IT Governance Institute.

[6] Garzás, J., \& Paulk, M. C. (2013). A case study of software process improvement with CMMI-DEV and Scrum in Spanish companies. Journal of Software: Evolution and Process, 25(12), 1325-1333.

[7] Marshall, C., \& Rossman, G. B. (2006). Designing Qualitative Research. Thousand Oaks: Sage Publication.

[8] Miles, M. B., \& Huberman, A. M. (1994). Qualitative Data Analysis. Newbury Park, CA: Sage.

[9] IT Governance Institute. (2010). Retrieved July 20, 2014, from ISACA website: http://www.isaca.org/KnowledgeCenter/Research/Documents/CMMI-Mapping-With-COBIT-FINAL-R esearch.pdf

[10] Lincoln, Y. S., \& Guba, E. A. (1985). Naturalistic Inquiry. Beverly Hills, CA: Sage.

[11] Creswell, J. W. (2007). Qualitative Inquiry and Research Design: Choosing Among Five Traditions (2nd ed.). Thousand Oaks, CA: Sage.

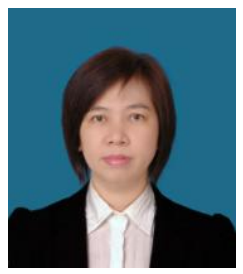

Lily Puspa Dewi received the master degree in information system from Institut Teknologi Sepuluh Nopember (ITS) in Surabaya, Indonesia. Currently, she is serving as a lecturer at the Informatics Department, Petra Christian University, Surabaya, Indonesia. Her research interests include information system-organizational and market interaction according to both computational and economic objective. 


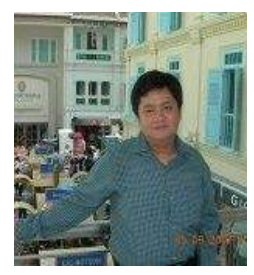

Ibnu Gunawan was born at Surabaya in 1979. He studied his master degree at ITS Surabaya, Indonesia. Beside his daily activities as a lecturer, he also a freelance auditor, and his research interests is in IS audit, information technology development.

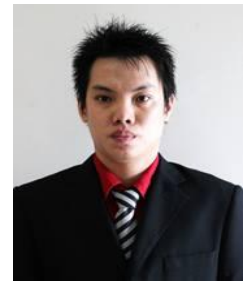

Raymond Weily was born at Ambon in 1991. He studied his bachelor degree at Petra University Surabaya, Indonesia. Beside his daily activities, he is as an internal auditor at PT. Bank Sinarmas, Tbk since April 2013 until now. 